WellBeing International

WBI Studies Repository

1985

\title{
Ethical Aspects of Animal Experimentation
}

\author{
Wolfgang Scharmann
}

Follow this and additional works at: https://www.wellbeingintlstudiesrepository.org/acwp_arte

Part of the Animal Experimentation and Research Commons, Animal Studies Commons, and the Bioethics and Medical Ethics Commons

\section{Recommended Citation}

Scharmann, W. (1985). Ethical aspects of animal experimentation. In M.W. Fox \& L.D. Mickley (Eds.), Advances in animal welfare science 1985/86 (pp. 87-90). Washington, DC: The Humane Society of the United States.

This material is brought to you for free and open access by WellBeing International. It has been accepted for inclusion by an authorized administrator of the WBI Studies Repository. For more information, please contact wbisr-info@wellbeingintl.org.

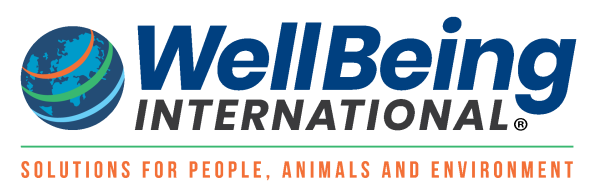




\section{ETHICAL ASPECTS OF ANIMAL EXPERIMENTATION}

\section{Wolfgang Scharmann}

Bundesgesundheitsamt

Postfach D-1000

Berlin 33 West Germany

If inquiries are made of people regarding their attitudes towards animal experimentation, there will no doubt be various answers corresponding to the different ethical attitudes today. Three principle points of view are imaginable. The two extremes are: an unrestricted support of all animal experiments; and a radical rejection of any such experiment. These two positions, in all likelihood, are taken by only a minority of the population. The majority will approve of animal experimentation in principle, however, only insofar as it is really necessary to preserve human life. So, the point of controversy arises from the question: When is an animal experiment necessary and indispensable?

The easiest solution, of course, (especially for legislators and authorities responsible for regulations on animal experimentation), would be to provide clearly defined statements as to which animal experiments are really necessary, that is, a catalogue of all experiments that are justifiable on ethical grounds. There cannot, however, be such a classification due to the fact that opinions regarding which animal experiments are necessary are largely divergent among the scientific as well as the lay community. Ethical demands will always be binding only in the individual case. Such demands can serve as a basis for legal regulations only after having become generally recognized.

So, the decision as to whether or not the purpose of an experiment is justifiable in terms of animal suffering would seem to rest with the individual scientist. The investigator will be able to accept this responsibility in a fair manner only if he/she recognizes the animal as a sentient, animated individual capable of suffering and with whom he/ she feels connected through a common history of evolution. To many 
scientists, this demand may seem to be emotionally exaggerated. Their knowledge of the animal has been formed by scientific studies which are almost exclusively limited to morphological description and measurement of physiological parameters which provide the young scientist with a unilateral mechanistic picture of the phenomenon of life. Modern veterinary medicine still adheres considerably to the Cartesian belief that animals are merely automatons, incapable of feeling distress and suffering. Therefore, we have to ask ourselves how to what degree the prevalence and extent of animal experimentation may be associated with the conversion of the animal into an object by the teachings of the natural sciences. Does the downgrading of the animal to the status of a measuring instrument, a live apparatus, reduce the threshold inhibiting humans from manipulating an animal, inflicting pain on it, or killing it? What is the value of compassion when the realization of scientific goals are at stake?

I ask this question, since I personally know very well how powerful the authority of science is, especially to young scientists. The investigations of Milgram (Milgram 1974) and others have revealed that science is regarded as an authority which is not questioned even if the scientific method appears to be doubtful. Although Milgram's studies have often been cited, they shall be described in brief because they may be significant also in regard to animal experimentation.

In his experiment, Milgram designated naive subjects as "teachers" and made them believe they would inflict electric shocks to a test person (the "learner") as part of a scientific study on learning capability. The "learner," however, was an actor who had been informed of the experiment. Guided by a scientist, most "teachers" inflicted the alleged shocks with rising intensity until there was the warning: "Danger-severe shock." Even protests and agonized screams of the "victim" did not cause most of the teachers to discontinue with the experiment when the scientist enjoined in continuing the shocks. They considered themselves as cooperators of an important research program which had to be performed to the benefit of society even if in its course nasty situations and sacrifices could not be avoided. An action which normally appeared evil to the naive subjects acquired a totally different meaning and legitimacy when carried out by the authority of science.

Albert Schweitzer, known for his precept of "reverence for life," deplored a tendency in his contemporaries to give up thinking for themselves and instead to rely on truths spoon-fed by authority. "The man," he said, "who has truly become a thinking being feels a compulsion to give to every will-to-live the same reverence for life that he gives to his own" (Schweitzer 1952). If we nevertheless consciously overrule the will-to-live of animals because we relate more strongly with the suffering fellow human being than with the suffering animal, we inflict guilt 
upon ourselves. In my opinion, only a human being conscious of becoming guilty and accepting guilt should be able to perform animal experiments.

Thus it will be more important than ever to raise and to strengthen the understanding by scientists, animal caretakers, and all others involved in animal experimentation of the will and the right of the animal to live. Approaches for this goal should be found above all else in the training curricula for scientists. The animals used for experiments should no longer be represented, viewed, and handled as objects, as is too often the case. A system of critical self-control of scientists by means of animal care or ethical committees (which exist in a number of countries already) may contribute to a sensitization of researchers. Conceivably, within this system, when research projects are discussed within ethical committees, the experimenter will be reminded of his/her responsibility to the animals. In the planning stages of experiments, the researcher will be expected to take into account scientific criteria, but show equal consideration for the animals even if this results in additional work and trouble. Such consideration and handling of the animal in the most careful manner possible will not only correspond to ethical concepts, but eventually also result in benefits for research as it is logical that experimental results will be of greater reliability when obtained using animals that are not stressed or in pain.

However, even if voting in favor of animal experimentation (with the reservation that experiments should be carried out only for indispensable purposes), we should ask ourselves whether the oppressingly high number of animal experiments does not exceed by far those justifiably necessary to maintain human life in dignity. In this respect, I refer to the great number of experiments conducted in connection with the control of civilization-associated diseases accounting for the major part of medicaments administered today in the industrialized nations. The major part of these illnesses have been caused by man himself when pursuing a wrong style of life. A comprehensive long-term study over a period of ten years (Schweiker 1982) involving seven thousand American male and female adults has demonstrated that the observance of a few positive health practices, such as not smoking, getting enough sleep and exercise, consuming alcohol only in moderation, maintaining proper weight, and eating breakfast, is of far greater importance for the maintenance of health than all the advances of twentieth century medicine, including those garnered by animal experiments.

I also ask myself whether in order to maintain man's existence, is it in fact necessary to introduce more than one thousand new chemicals annually into the market worldwide (Balls 1983)? Estimation of the associated risk requires experiments of between two thousand and six thousand animals per agent. One segment of these animal experiments is toxicological studies which involve severe suffering. When looking at 
the victim we must ask ourselves whether the price of economic growth, affluence, and a comfortable life (and animal experiments stand only for a fraction of this price) can still be justified.

Finally, I ask myself whether scientists, who thus far have decided upon the objective of their research mainly under their own responsibility, should not increasingly regard the public as their partner in discussion. The assertion of scientists that research would serve progress and human well-being has lost its credibility for many people. We have to ask whether or not there should be a re-thinking of what should be the essence of progress in the natural sciences. Will scientists alone be able to find a way out of the ecological crisis?

At least one thing has been clarified. We shall have to learn how to handle nature in a less destructive and more careful way. In my opinion, this would also include a higher examination of the will-to-live of animals, irrespective of whether they belong to wildlife or experimental species.

These questions and doubts should not be understood as attribution of guilt to a certain group, but rather as self-criticism and a suggestion to re-think our everyday actions. Such self-evaluation should also include the demand being voiced by so many people to reduce animal experiments, especially the painful ones. Their concerns should not be regarded simply as a nuisance impairing scientific work, although what is said by animal activists may often be exaggerated or even technically wrong. Rather it should also be understood as a call for a humane society in which nature is no longer taken as the object of exploitation but instead as a partner within the overall association of life.

\section{References}

Balls, M. 1983. Veterinary Record. 113: 398.

Milgram, S. 1974. Obedience to Authority: An Experimental View. London: Tavistock Schweiker, R.S. 1892. Public Health Reports. 97:196.

Schweitzer, A. 1952. Aus meinem Leben und Denken. Hamburg: Fischer-Bucherei. (English translation: 1961. Out of My Life and Thought. New York: Holt, Rinehart, and Winston.) 